DE

M E D I C I N A

T R O P I C A L

$\mathrm{DE}$

SÃO PAULO

JOURNAL OF THE SÃO PAULO INSTITUTE OF TROPICAL MEDICINE

\section{Morphological changes in the digestive system of 322 necropsies of patients with acquired immune deficiency syndrome: comparison of findings pre- and post-HAART (Highly Active Antiretroviral Therapy)}

\author{
Lucinda Calheiros Guimarães, Ana Cristina Araújo Lemos da Silva, Adilha \\ Misson Rua Micheletti, Everton Nunes Melo Moura, Mario Léon Silva- \\ Vergara, Sebastião Tostes Júnior, Sheila Jorge Adad
}

Universidade Federal do Triângulo Mineiro, Departamento de Patologia Especial, Uberaba, Minas Gerais, Brazil.

Correspondence to: Lucinda Calheiros Guimarães.

Universidade Federal do Triângulo Mineiro, Avenida Getúlio Guaritá, 130,

CEP 38022-200, Uberaba, MG, Brazil.

Tel: +553433185152 .

E-mail: lucindaguimaraes@yahoo.com.br

Received: 16 May 2016

Accepted: 22 September 2016

\section{ABSTRACT}

Involvement of the digestive system in AIDS pathologies or injuries is frequent. Aiming at comparing the frequency, the importance that these lesions have for death and the survival time in patients using or not using HAART, we studied 322 necropsies classified as follows: Group A - without antiretroviral drugs (185 cases); B - one or two antiretroviral drugs or HAART for less than six months ( 83 cases); C - HAART for six months or longer ( 54 cases). In the overall analysis of the digestive system, changes were present in $73.6 \%$ of cases. The most frequent was Candida infection (22.7\%), followed by cytomegalovirus (19.2\%), Histoplasma capsulatum (6.5\%), mycobacteria (5.6\%), and Toxoplasma gondii (4.3\%). T. gondii infection was more frequent in group A compared with group $\mathrm{C}$, and cytomegalovirus (CMV) was more frequent in group A compared with groups B and $\mathrm{C}(p<0.05) ; 2.2 \%$ of the deaths were due to gastrointestinal bleeding. Regarding the segments, only in the large intestine, and only cytomegalovirus, were more frequent in group A compared with group C. We conclude that digestive system infections are still frequent, even with the use of HAART. However, the average survival time in group $\mathrm{C}$ was more than three times greater than the one in group $\mathrm{A}$ and nearly double that of group B, demonstrating the clear benefit of this therapy.

KEYWORDS: Autopsy. Necropsy. AIDS. Digestive system. HAART.

\section{INTRODUCTION}

The digestive system is considered a "sanctuary" for the Human Immunodeficiency Virus (HIV) infection, being an organ with abundant lymphoid tissue, where the CD4 T lymphocytes and macrophages of the lamina propria are target cells for the viral infection. Active viral replication was observed in the intestinal lymphoid tissue of patients receiving antiretroviral therapy whose viral load was undetectable in the peripheral blood, suggesting that the digestive system is an important reservoir of HIV-infected cells, contributing to viral persistence ${ }^{1}$. The term HIV enteropathy refers to clinical, morphological and functional changes that affect infected patients from the acute phase to the late stages of the disease. These changes include diarrhea, increased intestinal mononuclear cell infiltration, increased intestinal permeability, malabsorption of bile acids and vitamin B12. These changes take place in the absence of fungal, bacterial or viral opportunistic infections. It is possible that HIV itself, through toxic or immune-mediated effects, is responsible for the enteropathy in these individuals ${ }^{2}$. In addition to HIV enteropathy, opportunistic infections and 
tumors are common causes of impairment of the digestive system in patients with Acquired Immunodeficiency Syndrome (AIDS) $)^{3,4,5}$. From the status of an invariably fatal disease at the beginning of the pandemic, AIDS has gone through several phases of clinical expression and prognosis, mainly due to discoveries regarding the virus itself and the physiopathology, allowing therapeutic advances that have resulted in major changes in the natural history of the disease ${ }^{6}$. The introduction of antiretroviral drugs in the Highly Active Antiretroviral Therapy (HAART), permits, currently, a prolonged survival and reduced incidence of opportunistic infections and neoplasms ${ }^{7}$. Although damage to the digestive system is common in AIDS, we did not find necropsy studies comparing the changes of this system in pre and post-HAART phases.

This study aimed at comparing the frequency of digestive system injuries in necropsies of patients with AIDS before and after HAART, the importance of these lesions for death and the survival time in patients using or not using HAART. Despite the global trend of reducing the number of necropsies due to an increased use of radiological and laboratory tests in pre-mortem diagnosis, necropsy remains important even today, as the discrepancy rates between pre-mortem and postmortem findings in AIDS vary from 42 to $74 \%$. Despite significant advances in diagnostic procedures, false-positive and false-negative diagnosis in the absence of necropsy still exist $t^{8,9,10,11,12}$. Necropsies are essential procedures for the quality control in university hospitals, and have helped to further understanding of the most frequent diseases in patients with HIV/AIDS ${ }^{13}$.

\section{MATERIALS AND METHODS}

This is a retrospective study of the digestive system in necropsies of individuals with HIV/AIDS held in the Department of Special Pathology/ Surgical Pathology Service of the Clinical Hospital of the Universidade Federal do Triângulo Mineiro (UFTM) from January 1989 to December 2012. This study was approved by the Research Ethics Committee (CEP) of the UFTM (CEP/ UFTM protocol No. 1871). Necropsies of individuals over 13 years of age diagnosed with AIDS, in life or postmortem, according to the 1993 Centers for Disease Control and Prevention (CDC) criteria of HIV infection classification, composed the study group ${ }^{14}$. The study excluded cases of necropsies that had no microscopic sampling of the digestive system and those whose medical records were not available for analysis.

After macroscopic examination during the autopsy, samples of digestive system segments (tongue, esophagus, stomach, small intestine, and large intestine) were collected, fixed in 10\% formaldehyde and processed for inclusion in paraffin. The standardization of samples for microscopy of the digestive system in our service consists in preparing at least one block containing fragments of each segment without macroscopic changes, as well as fragments of the lesions. Subsequently, histological sections were prepared from these samples and stained by the hematoxylin-eosin technique (HE).

The diagnosis of lesions found in the digestive system was made by the first author of the study, through the review of archived histological slides; when necessary, additional slides were prepared. When relevant, we proceeded applied special histochemical staining techniques for the identification of infectious agents or review of them: FiteFaraco for mycobacteria; Grocott, PAS, and mucicarmin for fungi. When indicated, an immunohistochemical study (polymer technique) was carried out, or a review of the slides previously prepared for microbiological confirmation: anti-toxoplasma (Novocastra-NCL-TG-TP3) 1: 1,200; anticytomegalovirus (Novocastra-NCL-CMV-pp65) 1: 200; antiherpes simplex virus (HSV Dako Type I and Type II) 1:2,000; anti-papillomavirus (BVP-1-Dako) 1:800; and to confirm neoplasms: anti-CD34 (Biocare Medical-CD34) 1:600 and anti-CD117 (Zeta corporation-CD117-YR145) 1:600.

Despite the macroscopic standardization, there were not histological sections of all segments of the digestive system in all the cases, the results being presented as absolute numbers and percentages of the total number of cases evaluated in each segment of the digestive system.

We consider HAART to be the use of at least three drugs (two reverse transcriptase inhibitors associated with a protease inhibitor or a non-nucleoside reverse transcriptase inhibitor). In our service, HAART was introduced for the treatment of AIDS patients in 1997. However, due to the heterogeneity in the use of HAART from that period, patients were classified into three groups: A - without the use of any antiretroviral drug; B - using one or two antiretroviral drugs for any time or on HAART for less than six months; $\mathrm{C}$ - on HAART during the last six months or more. Even after the beginning of HAART, there were untreated patients filling group A and patients with a non suppressive treatment, included in group B. We considered the period of six months of HAART treatment because, according to the literature ${ }^{15,16}$, less than six months of use would be insufficient to improve immunity.

The survival time was measured in months after the initial diagnosis of HIV infection, confirmed by serology. The cases in which the diagnosis of HIV infection was made during hospitalization that preceded the death, or from blood samples collected at necropsy, were considered as zero survival. 
The changes found in the three groups of patients were compared by statistical analysis using the Chi-square test $\left(\mathrm{x}^{2}\right)$, or Fisher's exact test, using the GraphPad InStat program. The statistical analysis of the survival time was performed using the Kaplan-Meier test with IBM SPSS Advanced Statistics program. The significance level for all the tests was $5 \%(p<0.05)$.

Disease of the digestive system was considered relevant to the death when it was indicated as the immediate cause of death or a contributing cause to death. These cases were analyzed separately and their ratio was calculated in relation to other patients.

Finally, we elaborated a form for clinical reports obtained from medical records and the requests for necropsies, which contained the case number, sex and age of the patient, whether they had AIDS or not, use or not of antiretroviral medication (study group), morphological data obtained by the microscopic review of each segment of the digestive system, cause of death given on the necropsy report, and the survival time after diagnosis of HIV infection.

\section{RESULTS}

In the 1989-2012 period 355 necropsies of patients with HIV/AIDS were performed at the UFTM (18\% of the total number of necropsies). This study included 322 necropsies of individuals with AIDS. The 33 excluded cases were: 3 younger than 13 years old; 9 were HIV positive but did not meet the AIDS criteria; 20 cases had no histological slides of the digestive system available for review; in 1 case the medical records for review and data collection were not found.

The average age of patients was $36.7 \pm 11$ years with a median of 35 years; there was a slight increase when comparing the $1989-1996$ period ( $34.2 \pm 11.5$ years) to the 1997-2012 (37.6 \pm 10.7$)$ one. Regarding the distribution by sex, a sharp rise was noted in the percentage of women when comparing the 1989-1996 period to the 1997-2012 one (18.8\% versus $33.2 \%)$.

Considering the use of antiretroviral medication, monotherapy was introduced at the UFTM in 1993, and HAART in 1997. Although only 90 of the 322 cases were diagnosed prior to 1997 (and were part of a previously published study ${ }^{17}$ ), most patients (185 cases; $57.4 \%$ ) in this study had no antiretroviral therapy, filling the criteria of group A; 83 (25.8\%) were enrolled in group $\mathbf{B}$; and only $54(16.8 \%)$ cases were included in group C. Table 1 shows the distribution of the 322 cases by age and sex according to the study group.

Two hundred and thirty-seven cases (73.6\%) had changes in some segment of the digestive system. Table 2 compares the frequency of injuries in the digestive system in the different study groups.

The AIDS-related injuries (194 cases; 81.9\%) were the most common changes, with a predominance of opportunistic infections (166 cases, 70\%) in relation to neoplasms (5 cases of Kaposi's sarcoma, 2.1\%). Other infectious diseases, neoplasms and conditions not related to AIDS were present in $43(18.1 \%)$ cases. The main changes

Table 1 - Distribution of the 322 necropsies of AIDS patients, according to age, sex and the study group

\begin{tabular}{lcccc}
\hline Group & A & B & C & Total \\
\hline Average age & $37.5 \pm 11.8$ & $35.4 \pm 10.3$ & $35.7 \pm 9.2$ & $\mathbf{3 6 . 7} \pm \mathbf{1 1}$ \\
Min.-max. age & $18-72$ & $17-67$ & $20-61$ & $\mathbf{1 7 - 7 2}$ \\
Male & $135(73 \%)$ & $61(73.5 \%)$ & $32(59.3 \%)$ & $\mathbf{2 2 8}(\mathbf{7 1} \%)$ \\
Female & $50(27 \%)$ & $22(26.5 \%)$ & $22(40.7 \%)$ & $\mathbf{9 4 ( 2 9 \% )}$ \\
\hline Number of cases & $\mathbf{1 8 5 ( 5 7 . 4 \% )}$ & $\mathbf{8 3 ( 2 5 . 8 \% )}$ & $\mathbf{5 4}(16.8 \%)$ & $\mathbf{3 2 2 ( 1 0 0 \% )}$ \\
\hline
\end{tabular}

Group A: without any antiretroviral medication; Group B: 1 or 2 antiretroviral drugs for any time or on HAART for less than the last six months; Group C: HAART in the last 6 months or more; Min.: minimum; Max.: maximum.

Table 2 - Distribution of cases according to the presence or absence of injuries in the digestive system, according to the study groups

\begin{tabular}{lcccc}
\hline & Group A & Group B & Group C & Total \\
\hline With injuries & $139(75.1 \%)$ & $61(73.5 \%)$ & $37(68.5 \%)$ & $\mathbf{2 3 7}(\mathbf{7 3 . 6 \% )}$ \\
Without injuries & $46(24.9 \%)$ & $22(26.5 \%)$ & $17(31.5 \%)$ & $\mathbf{8 5 ( 2 6 . 4 \% )}$ \\
\hline Total & $\mathbf{1 8 5 ( 1 0 0 \% )}$ & $\mathbf{8 3 ( 1 0 0 \% )}$ & $\mathbf{5 4 ( 1 0 0 \% )}$ & $\mathbf{3 2 2 ( 1 0 0 \% )}$ \\
\hline
\end{tabular}

Group A: without any antiretroviral medication; Group B: 1 or 2 antiretroviral drugs for any time or on HAART for less than the last six months; Group C: HAART in the last 6 months or more. $X^{2}$ test; $p>0.05$. 
found in the digestive system are presented in Table 3.

Considering all the segments of the digestive system, candidiasis was the most frequent abnormality $(22.7 \%)$, followed by cytomegalovirus infection $(19.2 \%)$, histoplasmosis (6.5\%), mycobacterial infection (5.6\%), and toxoplasmosis (4.3\%). T. gondii infection was more frequent in group A compared with group $\mathrm{C}$, and cytomegalovirus (CMV) was more frequent in group $\mathrm{A}$ compared with groups B and C $(p<0.05)$.

Culture was not performed for mycobacteria species identification; however, in 9 of the 18 cases, the morphological appearance was suggestive of Mycobacterium tuberculosis. Helminths were found in 20 cases, and in one of them there was simultaneous infestation by $S$. stercoralis and A. lumbricoides.
Relevant neoplasms were present in 11 cases: 5 Kaposi's sarcomas, 3 of them disseminated in the digestive system; 3 GIST (gastrointestinal stromal tumor), and 3 carcinomas (1 gastric signet ring cell adenocarcinoma, 1 metastatic undifferentiated carcinoma of the testis, 1 rectal squamous cell carcinoma). There were no cases of lymphoma in the digestive system in this study.

Analyzing each segment of the digestive system separately, in the tongue changes were observed in 78 $(55.7 \%)$ of the 140 cases in which it was possible to analyze the organ microscopically. The main changes are presented in Table 4. Candidiasis was the most frequent lesion; however, there was no statistically significant difference among groups. No tumors were found in the tongue.

Regarding the esophagus, lesions were observed in 142

Table 3 - Main morphological changes in the digestive system of the 322 necropsies of AIDS patients, according to the study group

\begin{tabular}{|c|c|c|c|c|c|c|c|c|}
\hline & \multicolumn{2}{|c|}{ Group A $(n=185)$} & \multicolumn{2}{|c|}{ Group B (n=83) } & \multicolumn{2}{|c|}{ Group C (n=54) } & \multicolumn{2}{|c|}{ Total $(n=322)$} \\
\hline & $(n)$ & $\%$ & $(\mathrm{n})$ & $\%$ & $(n)$ & $\%$ & $(n)$ & $\%$ \\
\hline \multicolumn{9}{|l|}{ INFECTIOUS AGENT } \\
\hline \multicolumn{9}{|l|}{ Protozoa } \\
\hline T. gondii & $13^{*}$ & 7 & 1 & 1.2 & 0 & 0 & 14 & 4.3 \\
\hline Cryptosporidium & 2 & 1 & 0 & 0 & 1 & 1.8 & 3 & 0.9 \\
\hline Isospora & 1 & 0.5 & 0 & 0 & 0 & 0 & 1 & 0.3 \\
\hline \multicolumn{9}{|l|}{ Fungi } \\
\hline Candida & 48 & 26 & 16 & 19.3 & 9 & 16.6 & 73 & 22.7 \\
\hline H. capsulatum & 14 & 7.5 & 4 & 4.8 & 3 & 5.5 & 21 & 6.5 \\
\hline C. neoformans & 8 & 4.3 & 3 & 3.6 & 1 & 1.8 & 12 & 3.7 \\
\hline P. brasiliensis & 2 & 1 & 0 & 0 & 1 & 1.8 & 3 & 0.9 \\
\hline \multicolumn{9}{|l|}{ Bacteria } \\
\hline Mycobacteria & 15 & 8.1 & 2 & 2.4 & 1 & 1.8 & 18 & 5.6 \\
\hline \multicolumn{9}{|l|}{ Virus } \\
\hline CMV & $49^{a b}$ & 26.4 & $7^{a}$ & 8.4 & $6^{b}$ & 11.1 & 62 & 19.2 \\
\hline HSV & 6 & 3.2 & 3 & 3.6 & 1 & 1.8 & 10 & 3.1 \\
\hline \multicolumn{9}{|l|}{ Helminths } \\
\hline S. stercoralis & 7 & 3.8 & 2 & 2.4 & 4 & 7.4 & 13 & 4 \\
\hline A. lumbricoides & 2 & 1 & 2 & 2.4 & 0 & 0 & 4 & 1.2 \\
\hline Taenia & 2 & 1 & 1 & 1.2 & 0 & 0 & 3 & 0.9 \\
\hline S. mansoni & 1 & 0.5 & 1 & 1.2 & 0 & 0 & 2 & 0.6 \\
\hline \multicolumn{9}{|l|}{ NEOPLASMS } \\
\hline Karposi's sarcoma & 2 & 1 & 1 & 1.2 & 2 & 3.7 & 5 & 1.5 \\
\hline Carcinoma & 1 & 0.5 & 2 & 2.4 & 0 & 0 & 3 & 0.9 \\
\hline GIST & 0 & 0 & 2 & 2.4 & 1 & 1.8 & 3 & 0.9 \\
\hline
\end{tabular}

Multiple infectious agents were simultaneously observed in some cases. Group A: without any antiretroviral medication; Group B: 1 or 2 antiretroviral drugs for any time or on HAART for less than the last six months; Group C: HAART in the last 6 months or more; CMV: cytomegalovirus; HSV: Herpes simplex virus; GIST: gastrointestinal stromal tumor. Fisher's exact test; * $p<0.05$ between the study groups $A$ and $C ;{ }^{a} p<0.05$ between the study groups $A$ and $B ;{ }^{b} p<0.05$ between the study groups $A$ and $C$. 
(52\%) of the 273 cases in which analysis was possible. The main changes were infectious and they are shown in Table 5; however, there was no statistically significant difference between the frequencies of the different injuries among the study groups. Two cases of chagasic megaesophagus were found and there was no reactivation of Chagas disease.

Considering the stomach, the microscopic analysis was possible in 303 of the 322 cases, finding changes in 104 $(34.3 \%)$ cases. The main changes are presented in Table 6; CMV infection was the most frequent lesion in the stomach; however, there was no statistically significant difference among groups.

Regarding the small intestine, the microscopic analysis was possible in 306 cases, observing changes in 79 (25.8\%).

Table 4 - Main morphological changes in 140 necropsies of AIDS patients in whom it was possible to analyze the tongue, according to the study group

\begin{tabular}{|c|c|c|c|c|c|c|c|c|}
\hline \multirow{2}{*}{ Tongue injuries } & \multicolumn{2}{|c|}{ Group A (n=82) } & \multicolumn{2}{|c|}{ Group B $(n=41)$} & \multicolumn{2}{|c|}{ Group C (n=17) } & \multicolumn{2}{|c|}{ Total $(n=140)$} \\
\hline & $(n)$ & $\%$ & $(n)$ & $\%$ & $(n)$ & $\%$ & $(n)$ & $\%$ \\
\hline Candidiasis & 27 & 32.9 & 10 & 24.4 & 8 & 47 & 45 & 32.1 \\
\hline Oral pilar leukoplasia & 8 & 9.7 & 6 & 14.6 & 1 & 5.9 & 15 & 10.7 \\
\hline Histoplasmosis & 5 & 6.0 & 0 & 0 & 0 & 0 & 5 & 3.6 \\
\hline Cryptococcosis & 2 & 2.4 & 0 & 0 & 0 & 0 & 2 & 1.4 \\
\hline CMV infection & 1 & 1.2 & 0 & 0 & 0 & 0 & 1 & 0.7 \\
\hline Herpetic infection & 1 & 1.2 & 0 & 0 & 0 & 0 & 1 & 0.7 \\
\hline Mycobacterial infection & 1 & 1.2 & 0 & 0 & 0 & 0 & 1 & 0.7 \\
\hline Toxoplasmosis & 1 & 1.2 & 0 & 0 & 0 & 0 & 1 & 0.7 \\
\hline Paracoccidioidomycosis & 1 & 1.2 & 0 & 0 & 0 & 0 & 1 & 0.7 \\
\hline
\end{tabular}

Concomitant lesions were present in 6 cases. Group A: without any antiretroviral medication; Group B: 1 or 2 antiretroviral drugs for any time or on HAART for less than the last six months; Group C: HAART in the last 6 months or more; n: number of cases; CMV - cytomegalovirus. $X^{2}$ test; $p>0.05$.

Table 5 - Main morphological changes in 273 necropsies of AIDS patients in whom it was possible to analyze the esophagus, according to the study group

\begin{tabular}{|c|c|c|c|c|c|c|c|c|}
\hline \multirow{2}{*}{ Esophagus injuries } & \multicolumn{2}{|c|}{ Group A (n=157) } & \multicolumn{2}{|c|}{ Group B (n=68) } & \multicolumn{2}{|c|}{ Group C (n=48) } & \multicolumn{2}{|c|}{ Total $(n=273)$} \\
\hline & $(\mathrm{n})$ & $\%$ & $(\mathrm{n})$ & $\%$ & $(n)$ & $\%$ & $(n)$ & $\%$ \\
\hline \multicolumn{9}{|l|}{ INFECTION } \\
\hline Candidiasis & 26 & 16.5 & 7 & 10.3 & 4 & 8.3 & 37 & 13.5 \\
\hline CMV infection & 23 & 14.6 & 7 & 10.3 & 5 & 10.4 & 35 & 12.8 \\
\hline Herpetic infection & 5 & 3.2 & 3 & 4.4 & 1 & 2 & 9 & 3.3 \\
\hline Histoplasmosis & 4 & 2.5 & 0 & 0 & 2 & 4.1 & 6 & 2.2 \\
\hline Cryptococcosis & 3 & 2 & 1 & 1.5 & 1 & 2 & 5 & 1.8 \\
\hline Mycobacterial infection & 4 & 2.5 & 0 & 0 & 0 & 0 & 4 & 1.5 \\
\hline Toxoplasmosis & 4 & 2.5 & 0 & 0 & 0 & 0 & 4 & 1.5 \\
\hline Chagasic megaesophagus & 1 & 0.6 & 0 & 0 & 1 & 2 & 2 & 0.7 \\
\hline \multicolumn{9}{|l|}{ NEOPLASMS } \\
\hline Karposi's sarcoma & 1 & 0.6 & 1 & 1.5 & 0 & 0 & 2 & 0.7 \\
\hline Carcinoma & 0 & 0 & 1 & 1.5 & 0 & 0 & 1 & 0.4 \\
\hline Squamous papilloma & 0 & 0 & 0 & 0 & 1 & 2 & 1 & 0.4 \\
\hline $\begin{array}{l}\text { NONINFECTIOUS } \\
\text { EROSIONS/ULCERS }\end{array}$ & 10 & 6.4 & 3 & 4.4 & 6 & 12.5 & 19 & 7 \\
\hline
\end{tabular}

Concomitant lesions were present in 13 cases. Group A: without any antiretroviral medication; Group B: 1 or 2 antiretroviral drugs for any time or on HAART for less than the last six months; Group C: HAART in the last 6 months or more; CMV- cytomegalovirus. $X^{2}$ test; $p>0.05$. 
Table 6 - Main morphological changes in 303 necropsies of AIDS patients in whom it was possible to analyze the stomach, according to the study group

\begin{tabular}{|c|c|c|c|c|c|c|c|c|}
\hline \multirow{2}{*}{ Stomach Injuries } & \multicolumn{2}{|c|}{ Group A $(n=171)$} & \multicolumn{2}{|c|}{ Group B $(n=80)$} & \multicolumn{2}{|c|}{ Group C (n=52) } & \multicolumn{2}{|c|}{ Total $(n=303)$} \\
\hline & (n) & $\%$ & (n) & $\%$ & (n) & $\%$ & (n) & $\%$ \\
\hline \multicolumn{9}{|l|}{ INFECTION } \\
\hline CMV infection & 15 & 8.8 & 3 & 3.7 & 3 & 5.7 & 21 & 6.9 \\
\hline Toxoplasmosis & 9 & 5.3 & 0 & 0 & 0 & 0 & 9 & 3 \\
\hline Strongyloidiasis & 2 & 1.2 & 2 & 2.5 & 3 & 5.7 & 7 & 2.3 \\
\hline Histoplasmosis & 4 & 2.4 & 0 & 0 & 2 & 3.8 & 6 & 2 \\
\hline Cryptococcosis & 4 & 2.4 & 1 & 1.2 & 0 & 0 & 5 & 1.6 \\
\hline H. pylori & 2 & 1.2 & 2 & 2.5 & 0 & 0 & 4 & 1.3 \\
\hline Candidiasis & 3 & 1.8 & 0 & 0 & 0 & 0 & 3 & 1 \\
\hline Cryptosporidiosis & 2 & 1.2 & 0 & 0 & 0 & 0 & 2 & 0.7 \\
\hline \multicolumn{9}{|l|}{ NEOPLASMS } \\
\hline Karposi's sarcoma & 2 & 1.2 & 1 & 1.2 & 1 & 1.9 & 4 & 1.3 \\
\hline Carcinoma & 1 & 0.6 & 0 & 0 & 0 & 0 & 1 & 0.3 \\
\hline GIST & 0 & 0 & 1 & 1.2 & 1 & 1.9 & 2 & 0.7 \\
\hline \multicolumn{9}{|c|}{ NONINFECTIOUS ULCERS } \\
\hline Acute & 6 & 3.5 & 2 & 2.5 & 0 & 0 & 8 & 2.6 \\
\hline Chronic Peptic & 5 & 3.0 & 2 & 2.5 & 0 & 0 & 7 & 2.3 \\
\hline Nonspecific & 0 & 0 & 1 & 1.2 & 0 & 0 & 1 & 0.3 \\
\hline
\end{tabular}

Concomitant lesions were present in 9 cases. Group A: without using any antiretroviral medication; Group B: 1 or 2 antiretroviral drugs for any time or on HAART for less than the last six months; Group C: HAART in the last 6 months or more; n: number of cases; GIST: gastrointestinal stromal tumor; CMV- cytomegalovirus; $X^{2}$ test; $p>0.05$.

The main changes are presented in Table 7; cytomegalovirus infection and histoplasmosis were the most common injuries in this segment; however, there was no statistically significant difference among groups.

Considering the large intestine, lesions were observed in $123(41 \%)$ of the 301 cases in which microscopic analysis was possible. The main changes are presented in Table 8; CMV infection was more frequent in group $\mathrm{A}$ in comparison with group C $(p<0.05)$. One case of chagasic megacolon was found, but it did not present reactivation of Chagas disease.

This study also evaluated whether the changes of the digestive system were relevant to death, which occurred in $14(4.3 \%)$ cases. In $7(2.2 \%)$ of them, the immediate cause of death was hypovolemic shock secondary to gastrointestinal bleeding, and in the other 7 cases, the digestive system lesions have contributed to death.

Regarding the survival time and the use or not of HAART, the analysis was performed in 297 (92\%) of the 322 cases (Figure 1). The Kaplan-Meier test showed a better survival rate in group C compared to the other groups, and this difference was statistically significant, showing a clear benefit of HAART.

\section{DISCUSSION}

Considering PubMed (www.ncbi.nlm.nih.gov/pubmed) as a research source, this seems to be the first study of necropsies in AIDS patients that compares morphological changes of the digestive system pre- and post-HAART. The main advantage of necropsy is that it enables a broad analysis of the digestive system segments, despite the presence of mucosa autolysis.

In this study, an increase in the percentage of the female population with AIDS was observed, from 18.8\% in the 1989-1996 period to $33.2 \%$ in the $1997-2012$ period, a feature described as the phenomenon of feminization of the disease $\mathrm{e}^{18}$. The feminization of AIDS is related to the increase in heterosexual transmission of HIV observed in recent years of the epidemic ${ }^{19}$.

The damage to the digestive system in this study was present in $73.6 \%$ of cases, Candida sp. and CMV being the most frequent etiological agents. These findings are in agreement with other necropsy studies that showed changes in the digestive system in $82.3 \%$ of 45 necropsies and $61.2 \%$ of 49 necropsies ${ }^{3,4}$. Our previous necropsy study performed in the pre-HAART phase showed changes in the digestive 
Table 7 - Main morphological changes in 306 necropsies of AIDS patients in whom it was possible to analyze the small intestine, according to the study group

\begin{tabular}{|c|c|c|c|c|c|c|c|c|}
\hline \multirow{2}{*}{ Small intestine injuries } & \multicolumn{2}{|c|}{ Group $A(n=174)$} & \multicolumn{2}{|c|}{ Group B (n=81) } & \multicolumn{2}{|c|}{ Group C (n=51) } & \multicolumn{2}{|c|}{ Total $(n=306)$} \\
\hline & $(n)$ & $\%$ & $(n)$ & $\%$ & (n) & $\%$ & (n) & $\%$ \\
\hline \multicolumn{9}{|l|}{ INFECTION } \\
\hline CMV infection & 13 & 7.5 & 3 & 3.7 & 2 & 3.9 & 18 & 5.9 \\
\hline Histoplasmosis & 8 & 4.6 & 3 & 3.7 & 2 & 3.9 & 13 & 4.2 \\
\hline Mycobacterial infection & 9 & 5.2 & 0 & 0 & 1 & 1.9 & 10 & 3.3 \\
\hline Strongyloidiasis & 3 & 1.7 & 2 & 2.5 & 4 & 7.8 & 9 & 3 \\
\hline Cryptococcosis & 5 & 2.9 & 2 & 2.5 & 0 & 0 & 7 & 2.3 \\
\hline Ascaridiasis & 2 & 1.1 & 2 & 2.5 & 0 & 0 & 4 & 1.3 \\
\hline Toxoplasmosis & 2 & 1.1 & 0 & 0 & 0 & 0 & 2 & 0.6 \\
\hline Cryptosporidiosis & 1 & 0.6 & 0 & 0 & 1 & 1.9 & 2 & 0.6 \\
\hline Schistosomiasis & 0 & 0 & 1 & 1.2 & 0 & 0 & 1 & 0.3 \\
\hline Teniasis & 1 & 0.6 & 0 & 0 & 0 & 0 & 1 & 0.3 \\
\hline \multicolumn{9}{|l|}{ NEOPLASMS } \\
\hline Karposi's sarcoma & 2 & 1.1 & 0 & 0 & 1 & 1.9 & 3 & 1 \\
\hline GIST & 0 & 0 & 1 & 1.2 & 0 & 0 & 1 & 0.3 \\
\hline \multicolumn{9}{|c|}{ NONINFECTIOUS ULCERS } \\
\hline Nonspecific & 2 & 1.1 & 1 & 1.2 & 1 & 1.9 & 4 & 1.3 \\
\hline Chronic Peptic & 1 & 0.6 & 0 & 0 & 0 & 0 & 1 & 0.3 \\
\hline INFARCTION & 1 & 0.6 & 1 & 1.2 & 1 & 1.9 & 3 & 1 \\
\hline
\end{tabular}

Concomitant lesions were present in 5 cases. Group A: without using any antiretroviral medication; Group B: 1 or 2 antiretroviral drugs for any time or on HAART for less than the last six months; Group C: HAART in the last 6 months or more; GIST: gastrointestinal stromal tumor; CMV - cytomegalovirus; $X^{2}$ test; $p>0.05$.

system in $78.5 \%$ of cases $^{17}$. The higher prevalence of infection by Candida sp. ${ }^{17,20,21}$ and $\mathrm{CMV}^{3,4,5,22}$ among other infectious agents, and neoplasms, have also been reported in necropsy and biopsy studies, both in general studies, and also in those solely concerning the digestive system.

Candidiasis was the most frequent infection in this study. In addition to the damage to the tongue and esophagus, the most common sites, stomach and large intestine were also committed. In all of the cases analyzed, this infection was only located in the mucosa, with pseudo-hyphae and spores in areas of the squamous epithelium with hyper parakeratosis, or fibrin-leukocyte pseudo membranes, occasionally causing erosions. However, no deep invasion of tissues was found. In only two of these cases there was concomitant lung disease that caused death; neither of them were on HAART. In a study of esophageal biopsies of patients with HIV infection ${ }^{23}$, the invasion of fungi of the muscular and esophageal adventitia was observed, in addition to vascular invasion, which would allow the development of disseminated infections by Candida sp. These changes were not observed in this study.

$\mathrm{CMV}$ is one of the most frequent opportunistic agents found in necropsy studies of the digestive system ${ }^{4,24,25,26}$. In this study, we found a statistically significant association between the occurrence of CMV and the nonuse of HAART. Cytomegalovirus infection was observed in all the segments of the digestive system, the infection being most common in the stomach and intestines. Cytomegalic inclusions were present in endothelial cells, epithelial cells and stromal cells of the lamina propria, associated or not with erosions and mucosal ulcers. In fact, clinical manifestations of CMV infection are variable, depending on the lesions in the affected tissues. In the digestive system, advanced disease is represented by erosion or mucosal ulceration, causing watery diarrhea, and the differential diagnosis of this condition with other causes of diarrhea in patients with AIDS is very difficult ${ }^{27}$, requiring histopathological confirmation for the definitive diagnosis. In the large intestine, a statistically significant association between CMV infection and the nonuse of HAART was noted.

Still regarding the large intestine, there was a statistically significant association between the occurrence of different types of injuries and the absence of HAART. In this study, there was a reduced frequency of changes in the colon in 
Table 8 - Main morphological changes in 301 necropsies of AIDS patients in whom it was possible to analyze the large intestine, according to the study group

\begin{tabular}{|c|c|c|c|c|c|c|c|c|}
\hline \multirow[t]{2}{*}{ Large intestine injuries } & \multicolumn{2}{|c|}{ Group A $(n=173)$} & \multicolumn{2}{|c|}{ Group B $(n=77)$} & \multicolumn{2}{|c|}{ Group C (n=51) } & \multicolumn{2}{|c|}{ Total $(n=303)$} \\
\hline & $(n)$ & $\%$ & $(n)$ & $\%$ & $(n)$ & $\%$ & $(n)$ & $\%$ \\
\hline \multicolumn{9}{|l|}{ INFECTION } \\
\hline CMV infection & $27^{*}$ & 15.6 & 6 & 7.8 & $2^{*}$ & 4 & 35 & 11.6 \\
\hline Histoplasmosis & 10 & 5.8 & 4 & 5.2 & 2 & 4 & 16 & 5.3 \\
\hline Mycobacterial infection & 12 & 7 & 2 & 2.6 & 0 & 0 & 14 & 4.6 \\
\hline Strongyloidiasis & 5 & 2.9 & 1 & 1.3 & 3 & 5.9 & 9 & 3 \\
\hline Cryptococcosis & 4 & 2.3 & 2 & 2.6 & 1 & 2 & 7 & 2.3 \\
\hline Toxoplasmosis & 3 & 1.7 & 1 & 1.3 & 0 & 0 & 4 & 1.3 \\
\hline Candidiasis & 3 & 1.7 & 0 & 0 & 0 & 0 & 3 & 1 \\
\hline Paracoccidioidomycosis & 2 & 1.2 & 0 & 0 & 1 & 2 & 3 & 1 \\
\hline Schistosomiasis & 1 & 0.6 & 1 & 1.3 & 0 & 0 & 2 & 0.7 \\
\hline Teniasis & 1 & 0.6 & 1 & 1.3 & 0 & 0 & 2 & 0.7 \\
\hline Cryptosporidiosis & 1 & 0.6 & 0 & 0 & 0 & 0 & 1 & 0.3 \\
\hline Isosporiasis & 1 & 0.6 & 0 & 0 & 0 & 0 & 1 & 0.3 \\
\hline Chagasic Megacolon & 0 & 0 & 0 & 0 & 1 & 2 & 1 & 0.3 \\
\hline \multicolumn{9}{|l|}{ NEOPLASMS } \\
\hline Karposi's sarcoma & 1 & 0.6 & 0 & 0 & 0 & 0 & 1 & 0.3 \\
\hline Carcinoma & 0 & 0 & 1 & 1.3 & 0 & 0 & 1 & 0.3 \\
\hline Lipoma & 1 & 0.6 & 0 & 0 & 0 & 0 & 1 & 0.3 \\
\hline NONINFECTIOUS ULCERS & 3 & 1.7 & 2 & 2.6 & 3 & 5.9 & 8 & 2.6 \\
\hline INFARCTION & 2 & 1.2 & 1 & 1.3 & 1 & 2 & 4 & 1.3 \\
\hline
\end{tabular}

Concomitant injuries were present in 12 cases. Group A: without using any antiretroviral medication; Group B: 1 or 2 antiretroviral drugs for any time or on HAART for less than the last six months; Group C: HAART in the last 6 months or more; n: number of cases; CMV - cytomegalovirus; *Fisher's exact test; $p<0.05$.

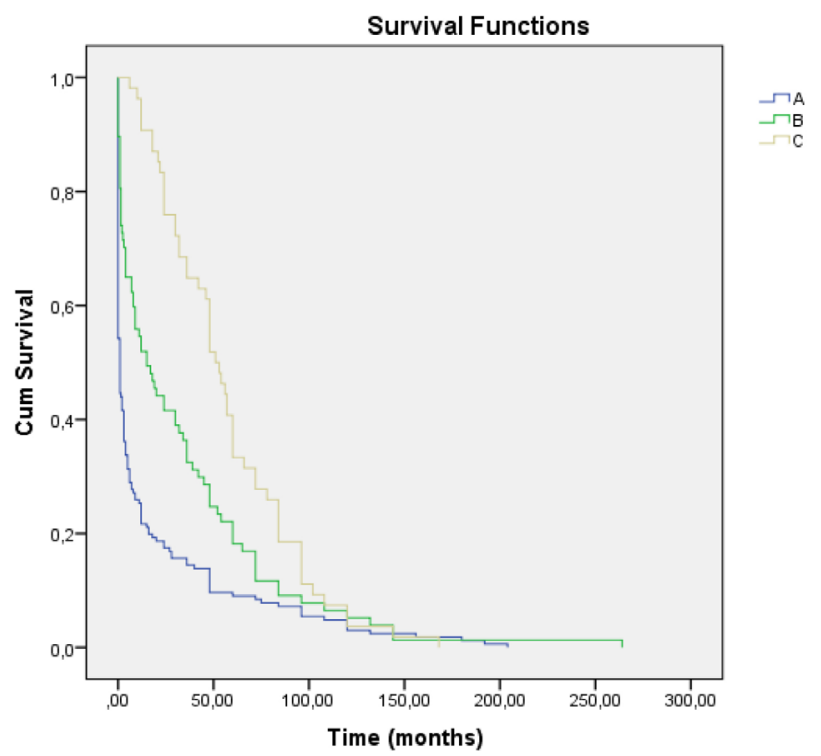

Figure 1 - Survival time (in months) after the diagnosis of HIV infection in 297 of the 322 cases submitted to necropsy, in whom it was possible to obtain this information, according to the study group (Kaplan-Meier test)
47.4\% of patients without HAART in comparison with $31.4 \%$ in those on HAART. Biopsy studies have shown a reduction in the frequency of changes in the digestive tract, from $38 \%$ before the introduction of HAART to $19 \%$ after its introduction ${ }^{28}$.

Histoplasmosis was the third most frequent infection (6.5\%), being present in all the segments of the digestive system, similar to the rate found in other South American studies $^{29,30}$. South and Central America are considered endemic areas for histoplasmosis ${ }^{13,31}$. A Brazilian study that analyzed biopsies of the digestive system showed a decreased histoplasmosis frequency after the introduction of HAART ${ }^{32}$.

Mycobacterial infection occurred in 5.6\% of cases, being systemic and constituting an immediate or contributory cause to death in all of them. Indeed, in developing countries, tuberculosis is still a major cause of death ${ }^{9,11}$ even after the introduction of HAART. Possible explanations include the poor adherence to treatment, drug resistance and late diagnosis of the disease. 
Analyzing the whole digestive system, $T$. gondii was found in $4.3 \%$ of cases in this study and there was a statistically significant association between toxoplasmosis and the nonuse of HAART. On the other hand, a Brazilian clinical study showed an increased toxoplasmosis frequency in the post-HAART phase when biopsies of the digestive system were analyzed, and the increment was attributed to the use of more accurate diagnostic methods ${ }^{32}$. The frequency of toxoplasmosis in necropsy studies is quite variable, ranging from a total absence of infection ${ }^{3,4}$ to rates of up to $26 \%$ in areas with high prevalence of $T$. gondii infection $^{20}$. In Brazil, the prevalence of anti-Toxoplasma antibodies in the general population ranges from 50 to $80 \%^{33}$. In AIDS, immunodeficiency favors the endogenous reactivation of the agent and the emergence of disseminated forms of the disease, affecting even the digestive system.

Chagas disease, a common infection in the area of this study, was observed in two cases: one with megaesophagus and the other with megaesophagus and megacolon; neither of them presented reactivation of Chagas disease, a condition that is related to AIDS.

In several necropsies, the association of different infectious agents and tumors in the same segment or in different segments of the digestive system was observed. Similar conditions were found in $37.7 \%$ of cases in another study of AIDS patients who evolved to death and had their digestive systems studied after necropsy ${ }^{3}$. The coexistence of different conditions highlights the fact that even after the diagnosis of an opportunistic infection, one should not stop searching for other possible etiologies ${ }^{21}$.

Among the malignancies found in this study, only Kaposi's sarcoma is related to AIDS, having been found in all the segments studied, except in the tongue, in a total of 5 cases $(2.1 \%)$. None of the other malignancies found ( 3 GIST, 3 carcinomas - 1 gastric adenocarcinoma cells in signet ring, 1 metastatic undifferentiated carcinoma of the testis, 1 rectal squamous cell carcinoma) are considered to be related to AIDS. The low incidence of malignancies also occurred in other necropsy studies, not only in Brazil $1^{3,29,34,35}$, but also in foreign studies that analyzed necropsy and biopsy samples ${ }^{9,21}$.

In developed countries, the incidence of neoplasms unrelated to AIDS has increased after the introduction of HAART due to the higher survival and aging of patients ${ }^{36}$. Several foreign studies reported malignancies as, currently, one of the leading causes of death in AIDS patients, along with other causes unrelated to AIDS, such as drug overdose, suicide, violence, liver and cardiovascular diseases ${ }^{8,37,38,39}$.

In recent reports of the post-HAART era, statistically significant increments were observed in the frequencies of gastroesophageal reflux disease, digestive inflammatory diseases, gastric ulcer and Helicobacter pylori infection ${ }^{21,40}$. These studies were carried out using biopsy samples. With necropsy material, as in the present study, autolysis hinders the diagnosis of Helicobacter pylori and Cryptosporidium infection, agents that infect the mucosal surface, as well as of HIV enteropathy, reflux esophagitis and gastritis. Gastric peptic ulcers were present in seven patients and duodenal peptic ulcers in one case; however, without significant association in any of the studied groups. Idiopathic esophageal ulcers (without identified infectious agents) were noted in 19 (7\%) patients. Nkuize et al. ${ }^{40}$ observed a reduction in Candida sp. esophagitis frequency, nonspecific esophageal ulcers and Kaposi's sarcoma over 17 years of study. The same authors reported the presence of Candida sp. esophagitis in 16\% of patients on HAART. Another study using biopsy material showed a prevalence of 9\% of opportunistic infections in AIDS patients on HAART $^{41}$. These authors attributed this finding mainly to the non-adherence to treatment, which occurred in $40 \%$ of cases. In patients whose treatment was carried out correctly, possible causes for the occurrence of opportunistic infections despite HAART include viral resistance to anti-HIV drugs, drug interactions, and decreased drug bioavailability.

Regarding the relevance of digestive system diseases to the death of patients, it was observed that only in $4.3 \%$ of cases these changes were the cause, or a contributory factor to death. In fact, diseases of the digestive system are important causes of morbidity and decreased quality of life in patients with AIDS, being among the most frequent diseases in these patients ${ }^{21}$.

We conclude that, in this study, analyzing the whole digestive system, there was a decreased frequency of toxoplasmosis and CMV in the group treated with HAART compared with the group without antiretroviral treatment. In the analysis made according to the digestive system segment, only in the large intestine, and only with respect to CMV infection, there was a frequency reduction in the group on HAART compared with the group without the use of antiretroviral drugs. Our results confirm that the digestive system is a common site of disease related to HIV/AIDS, even with the introduction of HAART, although digestive diseases are uncommon causes of death in these patients. The longer survival time of HAART users shows a clear benefit of HAART, corroborating clinical studies.

\section{ACKNOWLEDGEMENTS}

To the Conselho Nacional de Desenvolvimento Científico e Tecnológico (CNPq): Grant number 478955/2012-0 and the Universidade Federal do Triângulo Mineiro (UFTM). 


\section{REFERENCES}

1. Dandekar S. Pathogenesis of HIV in the gastrointestinal tract. Curr HIV/AIDS Rep. 2007;4:10-5.

2. Kotler DP, Gaetz HP, Lange M, Klein EB, Holt PR. Enteropathy associated with the acquired immunodeficiency syndrome. Ann Intern Med. 1984;101:421-8.

3. Carvalho MG, Rodrigues MA, Marques ME, Franco M, Montenegro MR. Lesões do trato gastrointestinal na síndrome da imunodeficiência adquirida: estudo de 45 necrópsias consecutivas. Rev Soc Bras Med Trop. 1994;27:135-41.

4. Lanjewar DN, Anand BS, Genta R, Maheshwari MB, Ansari MA, Hira SK, et al. Major differences in the spectrum of gastrointestinal infections associated with AIDS in India versus the west: an autopsy study. Clin Infect Dis. 1996;23:482-5.

5. Markowitz GS, Concepcion L, Factor SM, Borczuk AC. Autopsy patterns of disease among subgroups of an inner-city Bronx AIDS population. J Acquir Immune Defic Syndr Hum Retrovirol. 1996;13:48-54.

6. Gallo RC. A reflection on HIV/AIDS research after 25 years. Retrovirology. 2006;3:72.

7. Wilcox CM, Saag MS. Gastrintestinal complications of HIV infection: changing priorities in the HAART era. Gut. 2008;57:861-70.

8. Beadsworth MB, Cohen D, Ratcliffe L, Jenkis N, Taylor W, Campbell F, et al. Autopsies in HIV: still identifying missed diagnoses. Int J STD AIDS. 2009;20:84-6.

9. Lanjewar DN. The spectrum of clinical and pathological manifestations of AIDS in a consecutive series of 236 autopsied cases in Mumbai, India. Patholog Res Int. 2011;2011:547618.

10. Silva AC, Rodrigues BS, Micheletti AM, Tostes S Jr, Meneses AC, Silva-Vergara ML, et al. Neuropathology of AIDS: an autopsy review of 284 cases from Brazil comparing the findings pre- and post-HAART (Highly Active Antiretroviral Therapy) and pre- and postmortem correlation. AIDS Res Treat. 2012;2012:186850

11. Souza SL, Feitoza PV, Araújo JR, Andrade RV, Ferreira LC. Causas de óbito em pacientes com síndrome da imunodeficiência adquirida, necropsiados na Fundação de Medicina Tropical do Amazonas. Rev Soc Bras Med Trop. 2008;41:247-51.

12. Wilkes MS, Fortin AH, Felix JC, Godwin TA, Thompson WG. Value of necropsy in acquired immunodeficiency syndrome. Lancet. 1988;2:85-8.

13. Adad SJ, Machado ME, Batista FC. Histoplasmose residual dos pulmões e linfonodos broncopulmonares em necrópsias realizadas em Uberaba, MG. Rev Soc Bras Med Trop. 1996;29:491-6.

14. 1993 revised classification system for HIV infection and expanded surveillance case definition for AIDS among adolescents and adults. MMWR Recomm Rep. 1992;41(RR-17):1-19.
15. Battegay M, Nüesch R, Hirschel B, Kaufmann GR. Immunology recovery and antiretroviral therapy in HIV-1 infection. Lancet Infect Dis. 2006;6:280-7.

16. Hunt PW, Deeks SG, Rodriguez B, Valdez H, Shade S, Abrams DI, et al. Continued CD4 cell count increases in HIVinfected adults experiencing 4 years of viral suppression on antiretroviral therapy. AIDS. 2003;17:1907-15.

17. Guimarães LC, Silva AC, Micheletti AM, Moura EN, SilvaVergara ML, Adad SJ. Morphological changes in the digestive system of 93 human immunodeficiency virus patients: an autopsy study. Rev Inst Med Trop Sao Paulo. 2012;54:89-93.

18. Ribeiro AF, Veras MA, Guerra MA. Infecção por HIV e AIDS. In: Focaccia R, editor. Veronesi: tratado de infectologia. $4^{\mathrm{a}}$ ed. São Paulo: Atheneu; 2009. p.137-56.

19. Szwarcwald CL, Bastos FI, Esteves MA, de Andrade CL. A disseminação da epidemia da AIDS no Brasil, no período de 1987-1996: uma análise espacial. Cad Saude Publica. 2000;16 Supp 1:7-19.

20. Hofman P, Saint-Paul MC, Battaglione V, Michiels JF, Loubière R. Autopsy findings in acquired immunodeficiency syndrome (AIDS). A report of 395 cases from the south of France. Pathol Res Pract. 1999;195:209-17.

21. Sincu N, Mocan S, Chiriac LC, Bataga S. An endoscopic and pathological survey of digestive tract disorders in patients infected with immunodeficiency virus monitored in the Clinic of Infectious Diseases from Tirgu Mures, Romania. Rom J Morphol Embryol. 2014;55:885-90.

22. Mohar A, Romo J, Salido F, Jessurun J, Ponce de León S, Reyes E, et al. The spectrum of clinical and pathological manifestations of AIDS in a consecutive series of autopsied patients in Mexico. AIDS. 1992;6:467-73.

23. Görnig M, Emmert-Buck M, Walsh TJ. Merkmale der Candidaösophagitis bei tumor-und AIDS-patienten: histopathologische studie an 23 patienten. Mycoses. 1997;40 Suppl 1:81-5.

24. Klatt EC, Shibata D. Cytomegalovirus infection in the acquired immunodeficiency syndrome. Clinical and autopsy findings. Arch Pathol Lab Med. 1988;112:540-4.

25. d'Arminio Monforte A, Vago L, Gori A, Antinori S, Franzetti F, Antonacci CM, et al. Clinical diagnosis of mycobacterial disease versus autopsy findings in 350 patients with AIDS. Eur J Clin Microbiol Infect Dis. 1996;15:453-8.

26. Netto JG, Collarile DC, Borges AF, Biancala ML, Stefano HN. Achados necroscópicos em pacientes com síndrome da imunodeficiência adquirida. Rev Paul Med. 1990;108:205-12.

27. Yarrish RL. Cytomegalovirus infections in AIDS. In: Wormser GP, editor. AIDS and other manifestations of HIV- infection. $2^{\text {nd }}$ ed. New York: Raven Press; 1992.

28. Huppmann AR, Orenstein JM. Opportunistic disorders of the gastrointestinal tract in the age of highly active antiretroviral therapy. Hum Pathol. 2010;41:1777-87.

29. Borges AS, Ferreira MS, Nishioka SA, Silvestre MT, Silva AM, 
Rocha A. Agreement between premortem and postmortem diagnoses in patients with acquired immunodeficiency syndrome observed at a Brazilian teaching hospital. Rev Inst Med Trop Sao Paulo. 1997;39:217-21.

30. Eza D, Cerrillo G, Moore DA, Castro C, Ticona E, Morales D, et al. Postmortem findings and opportunistic infections in HIV- positive patients from a public hospital in Peru. Pathol Res Pract. 2006;202:767-75.

31. Nacher M, Adenis A, Mc Donald S, Gomes MS, Singh S, Lima IL, et al. Disseminated histoplasmosis in HIV-infected patients in South America: a neglected killer continues on its rampage. PLOS Negl Trop Dis. 2013;7:e2319.

32. Nobre V, Braga E, Rayes A, Serufo JC, Godoy P, Nunes N, et al. Opportunistic infections in patients with AIDS admitted to an university hospital of the southeast of Brazil. Rev Inst Med Trop Sao Paulo. 2003;45:69-74.

33. Frenkel JK, Bermudez JE. Toxoplasmose. In: Focaccia R, editor. Veronesi: tratado de infectologia, $4^{\mathrm{a}}$ ed. São Paulo: Atheneu, 2009. p.1793-809.

34. Cury PM, Pulido CF, Furtado VM, da Palma FM. Autopsy findings in AIDS patients from a reference hospital in Brazil: analysis of 92 cases. Pathol Res Pract. 2003;199:811-4.

35. Micheletti AM, Macedo AC, Silva GB, Silva AC, Silva-Vergara ML, Murta EF, et al. Benign and malignant neoplasias in 261 necropsies for HIV- positive patients in the period of 1989 to 2008. Rev Inst Med Trop Sao Paulo. 2011;53:309-14.
36. Pinzone MR, Fiorica F, Di Rosa M, Malaguarnera G, Malaguarnera L, Cacopardo B, et al. Non-AIDS-defining cancers among HIV-infected people. Eur Rev Med Pharmacol Sci. 2012;16:1377-88.

37. Crum NF, Riffenburgh RH, Wegner S, Agan BK, Tasker SA, Spooner KM, et al. Comparisons of causes of death and mortality rates among HIV-infected persons: analysis of the pre-, early and late HAART (Highly Active Antiretroviral Therapy) eras. J Acquir Immune Defic Syndr. 2006;41:194200.

38. Krentz HB, Kliewer G, Gill MJ. Changing mortality rates and causes of death for HIV-infected individuals living in Southern Alberta, Canada from 1984 to 2003. HIV Med. 2005;6:99-106.

39. Sackoff JE, Hanna DB, Pfeiffer MR, Torian LV. Causes of death among persons with AIDS in the era of highly active antiretroviral therapy: New York City. Ann Intern Med. 2006; 145:397-406

40. Nkuize M, De Wit S, Muls V, Arvanitakis M, Buset M. Upper gastrointestinal endoscopic findings in the era of highly active antiretroviral therapy. HIV Med. 2010;11:412-7.

41. Mönkemüller KE, Lazemby AJ, Lee DH, Loudon R, Wilcox CM. Occurrence of gastrointestinal opportunistic disorders in AIDS despite the use of highly active antiretroviral therapy. Dig Dis Sci. 2005;50:230-4. 